\title{
Applying Synthetic Biology with Rational Design to Nature's Greatest Challenges: Bioengineering Immunotherapeutics for the Treatment of Glioblastoma
}

\author{
Leila A. Mashouf ${ }^{1,2, *} \mathbb{C}$, Janet $Y . W^{1}{ }^{1}\left(\mathbb{D}\right.$, Pavan Shah $^{3}$, Nivedha Kannapadi ${ }^{3}$ and Michael Lim ${ }^{1}$ \\ 1 Department of Neurosurgery, Stanford University Medical Center, Stanford, CA 94305, USA; \\ jntwu@stanford.edu (J.Y.W.); mklim@stanford.edu (M.L.) \\ 2 Harvard Medical School, Harvard University, Boston, MA 02115, USA \\ 3 Department of Neurosurgery, Johns Hopkins School of Medicine, Baltimore, MD 21205, USA; \\ shah@jhmi.edu (P.S.); nkannap1@jhmi.edu (N.K.) \\ * Correspondence: lmashouf@stanford.edu
}

check for

updates

Citation: Mashouf, L.A.; Wu, J.Y.;

Shah, P.; Kannapadi, N.; Lim, M. Applying Synthetic Biology with Rational Design to Nature's Greatest Challenges: Bioengineering Immunotherapeutics for the Treatment of Glioblastoma. Immuno 2022, 2, 40-51. https://doi.org/ 10.3390/immuno2010004 Academic Editor: Mehdi Najar

Received: 1 December 2021 Accepted: 24 December 2021 Published: 29 December 2021

Publisher's Note: MDPI stays neutral with regard to jurisdictional claims in published maps and institutional affiliations.

Copyright: (c) 2021 by the authors. Licensee MDPI, Basel, Switzerland. This article is an open access article distributed under the terms and conditions of the Creative Commons Attribution (CC BY) license (https:// creativecommons.org/licenses/by/ $4.0 /)$.

\begin{abstract}
Improvements in bioengineering methodology and tools have allowed for significant progress in the development of therapeutics and diagnostics in medicine, as well as progress in many other diverse industries, such as materials manufacturing, food and agriculture, and consumer goods. Glioblastomas present significant challenges to adequate treatment, in part due to their immune-evasive and manipulative nature. Rational-design bioengineering using novel scaffolds, biomaterials, and inspiration across disciplines can push the boundaries in treatment development to create effective therapeutics for glioblastomas. In this review, we will discuss bioengineering strategies currently applied across diseases and disciplines to inspire creative development for GBM immunotherapies.
\end{abstract}

Keywords: bioengineering; glioblastoma; synthetic biology; biomaterials; cell-free; sustainability

\section{Introduction}

Glioblastoma (GBM) has the most devastating prognosis of all primary brain tumors. Despite decades of research and therapeutic innovation, the median survival for GBM patients remains at only 15-16 months, even for patients receiving optimal multimodal therapy [1]. GBM has unique characteristics that make treating the disease and eradicating tumors particularly challenging. All tumors recur because the highly migratory and infiltrative nature of GBM renders surgical resections incomplete [2]. Additionally, because these tumors are largely located in the brain, any therapeutics given to patients must cross the blood-brain barrier (BBB), which blocks at least $98 \%$ of both small- and large-molecule drugs [3,4]. Moreover, once drugs cross the BBB, they must do so in quantities effective for treatment, which is another hurdle to overcome [3]. While the BBB is traditionally difficult to overcome, however, nanotechnologies present opportunities for innovation to help drug molecules access brain tissue [5].

GBM are "cold" solid tumors, which resist host immune responses by suppressing natural killer cells and inducing T-cell apoptosis [6,7]. They are also classified by high intratumoral clonal neoantigen heterogeneity, which presents a two-way challenge: drugs must target enough clonal neoantigens to be effective immunotherapeutics, but drugs that target a large amount of neoantigens risk also targeting healthy tissues $[6,8]$. Clonal neoantigen heterogeneity also contributes to T-cell exhaustion, a phenomenon that presents in several viral infections and tumor types but most severely in GBM [9]. T-cell exhaustion is most prevalent among tumor-infiltrating lymphocytes and prevents them from targeting GBM tumor cells, leading to high levels of T-cell dysfunction observed in murine GBM models as well as human patient-derived GBM cell lines [9]. GBM is additionally known for its plasticity, especially of druggable targets $[6,10]$. Furthermore, glioma-associated 
macrophages and microglia (GAMs) exhibit intratumoral spatial heterogeneity of inflammatory phenotypes; core GAMs have pro-inflammatory signatures while peripheral GAMs have anti-inflammatory signatures in GBM tumors [11,12]. These regional and spatial differences allow for GAMs to play important roles in tumor growth and evolution, including their function of inducing GBM cell migration and invasion [11,12]. Together, these factors present uniquely challenging difficulties in targeting GBM tumors for complete eradication and in developing successful treatments.

Immunotherapies and bioengineered medicines have emerged as a promising new approach to treating aggressive tumors and have undergone accelerated development in the past ten years. Novel therapeutic avenues include the development of immune checkpoint blockade therapeutics, chimeric antigen receptor T cells (CAR T cells), dendritic cell (DC) vaccines, and engineered nanomedicines. Checkpoint blockade therapies have drastically improved patient outcomes for melanoma [13] and non-small cell lung cancer [14]; engineered $\mathrm{T}$ cells have done the same for hematologic cancers [15,16] and are FDA-approved treatment modalities for those diseases [17]. Unfortunately, they have not been as effective for GBM. Anti-PD1 therapy, which targets a popular immune checkpoint, has not been effective as a monotherapy in GBM, and efficacy of combination checkpoint blockade treatment in GBM patients is not fully established [18,19]. Median patient survival from three different CAR T-cell trials for GBM has been less than one year, though a select few patients have had extended survival beyond two years [19]. The main barriers to success for these therapies include the challenging GBM factors mentioned previously, such as intratumoral clonal neoantigen heterogeneity and plasticity, as well as poor T-cell infiltration into the tumor microenvironment $[6,19]$. An exciting new category of immunotherapy candidates for GBM worth noting is dendritic cell vaccines: preliminary data from the Phase 3 trial for DCVax ${ }^{\circledR}$-L may show increased survival for patients with newly diagnosed GBM [2]. However, this study is still ongoing, and these results will need to be replicated before full approval for standard of care. Additionally, artificial antigen presenting cells (aAPCs) engineered to target cancer-specific ligands have shown promise in efficacy and manufacturability $[20,21]$.

While efforts to identify higher quality neoantigens and target mechanisms of resistance hold promise, progress in patient outcomes has been slow. To aid in these efforts, bioengineering and the rational design of novel therapeutics have been and should continue to be applied to allow for more dynamic iteration of candidate drugs to better counter the challenges that GBM presents for effective treatment, summarized in Table 1. Protein engineering and optimization can help therapeutics better overcome the blood-brain barrier, extend their half-life and stability in various environments, and add useful functionalities to agents that assist in tumor killing. Additionally, the use of engineered biomaterials and nanotechnology can improve the delivery of therapeutics and tumoral access, especially to and in the brain. Bioengineering has allowed for significant innovation thus far, both in the research pipeline through the development of novel immunotherapeutics against GBM and in reaching GBM patients in ongoing and future clinical trials [22]. 
Table 1. Summary table of opportunities and challenges for bioengineered therapies in GBM. Images created with Biorender.com.

\begin{tabular}{|c|c|c|c|}
\hline & Examples Discussed & Advantages & Challenges \\
\hline & $\begin{array}{l}\text { Immune checkpoint } \\
\text { inhibitor antibodies } \\
\text { (anti-PD-1, anti-CTLA-4) }\end{array}$ & $\begin{array}{l}\text { - Many antibodies are } \\
\text { already FDA approved for } \\
\text { use in GBM or solid tumors } \\
\text { - Well-tolerated safety profile }\end{array}$ & $\begin{array}{l}\text { - Clinical trials in GBM } \\
\text { lack impressive, } \\
\text { durable response } \\
\text { Typically expensive } \\
\text { to produce }\end{array}$ \\
\hline Alternative Scaffolds & $\begin{array}{l}\text { - Anticalins, Affibodies, } \\
\text { DARPins, Monobodies, etc }\end{array}$ & $\begin{array}{l}\text { High stability and long } \\
\text { half-life in vivo } \\
\text { Can be engineered with } \\
\text { multi specificity to tackle } \\
\text { GBM heterogeneity } \\
\text { - } \quad \text { Added functionalities } \\
\text { beyond Abs, such as linkers } \\
\text { Easy and } \\
\text { cost-effective manufacturing }\end{array}$ & $\begin{array}{ll}\text { - } & \text { No clinical trials } \\
\text { currently in GBM } \\
\text { - } \\
\text { imconcern for } \\
\text { immunogenicity } \\
\text { in vivo } \\
\text { Early stage of } \\
\text { investigation, much } \\
\text { more to learn in } \\
\text { terms of safety } \\
\text { and efficacy }\end{array}$ \\
\hline Engineered Cells \& Particles & $\begin{array}{ll}- & \text { CAR T cells } \\
- & \text { Artificial Antigen } \\
\text { - } & \text { Presenting Cells (aAPCs) } \\
& \text { Nanovesicles/Nanoparticles }\end{array}$ & $\begin{array}{l}\text { - Can modify cells to express } \\
\text { virtually any ligand } \\
\text { - } \quad \text { Stable in vivo } \\
\text { Long history of } \\
\text { investigation for many } \\
\text { applications, } \\
\text { including GBM }\end{array}$ & $\begin{array}{l}\text { - } \\
\text { Still rely on } \\
\text { trafficking of cells to } \\
\text { tumor site, known to } \\
\text { be a challenge in } \\
\text { GBM } \\
\text { CAR T cells have } \\
\text { been known to cause } \\
\text { cytokine storm and } \\
\text { other off-target } \\
\text { adverse effects }\end{array}$ \\
\hline
\end{tabular}

- $\quad$ Allows sustained release of particles or engineered cells, Polymeric Biomaterials

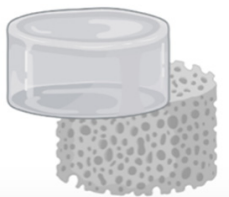

- $\quad$ Therapeutic-loaded hydrogels

- Vaccine-loaded biomaterials

- $\quad$ Cell traps therefore single implantation/injection can yield long-term therapy

- $\quad$ Can be used to trap highly migratory GBM cells and kill them, or trap exhausted/immunosuppressive $\mathrm{T}$ cells

- $\quad$ Long history of use in tissue engineering

- Ideal for drug delivery: self-assembly, complex structure formation, biocompatibility, and degradability

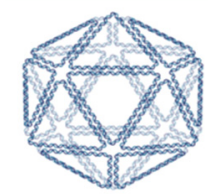

- $\quad$ DNA origami structures loaded with active therapeutics
- Can carry a variety of cargoes such as drugs, siRNA, CpG, proteins \& enzymes, and more
- Degradation of some polymer structures may be limited, may cause adverse irritation overtime if not biocompatible
- $\quad$ Fairly early in investigation, requires more testing for safety profile 
Table 1. Cont.

\begin{tabular}{|c|c|c|c|}
\hline & Examples Discussed & Advantages & Challenges \\
\hline Implantable Nanoreactors & $\begin{array}{l}\text { - Cell-free stabilized } \\
\text { enzymes for continuous, } \\
\text { dynamic therapy }\end{array}$ & $\begin{array}{l}\text { Can provide continuous, } \\
\text { robust conversion or } \\
\text { synthesis of molecule of } \\
\text { interest based on } \\
\text { environment } \\
\text { No limitations of } \\
\text { living cells } \\
\text { Can be loaded with } \\
\text { multiple enzymes to } \\
\text { perform a cascading } \\
\text { reaction pathway, or } \\
\text { multiple different reactions } \\
\text { to target heterogeneity } \\
\text { of GBM } \\
\text { Stable over months }\end{array}$ & $\begin{array}{l}\text { Very limited studies } \\
\text { exist on cell-free } \\
\text { stabilized enzymes } \\
\text { as a therapy, while } \\
\text { more precedent } \\
\text { exists in } \\
\text { biomanufacturing } \\
\text { Safety profile in vivo } \\
\text { is a possible concern } \\
\text { with a continuous } \\
\text { reaction system }\end{array}$ \\
\hline
\end{tabular}

\section{Current Investigations}

\subsection{Engineering Protein Therapeutics}

Creative modifications of protein-based therapeutics through engineering can introduce key properties necessary to address brain-tumor-specific challenges to treatment [23-28]. Active areas of exploration in protein optimization and engineering include the utilization of new protein formats and scaffolds that confer useful properties, half-life extension, stability enhancement, and the leveraging of multivalency and multi-specificity to increase target affinity and selectivity. As we will discuss, protein engineering has been applied in the development of many anti-GBM therapies currently available for patients, with significant room for improvement as advances in bioengineering allow for novel properties.

\subsubsection{Alternative Scaffolds}

While monoclonal antibodies $(\mathrm{mAb})$ therapies have afforded significant improvements in survival for certain cancers, their limitations are notable in treating intracranial malignancies, including their large size limiting extravasation and tissue penetration in solid tumors or non-vascularized regions [29,30]. Alternatives to whole IgG therapeutics, such as antibody fragments and non-IgG antibody mimetic scaffolds, have been increasingly investigated to improve the limitations of bulky $\mathrm{mAb}$ while preserving therapeutic power. Alternative non-IgG scaffolds are advantageous due to their smaller size, allowing access to tight binding pockets and increased tissue penetrance; their preserved folding in reducing environments, such as intracellular cytoplasm; and their ease of production through fermentation or chemical synthesis $[29,30]$. The most established of these alternative scaffolds include Anticalins, Affibodies, DARPins and Monobodies, although over 50 have been previously described and reviewed in-depth [30]. These scaffolds vary in secondary structure and can be rationally designed and selected based on the requirements in particular applications. For example, Anticalins are unique amongst this group for their ability to bind small molecules within a binding pocket [30]. One advantage of alternative scaffolds over native proteins is that they can be delivered through routes of administration that are not typically employed for protein therapeutics. For example, Anticalins (PRS060; NCT03384290) and Kunitz domains (NCT00455767) have been administered through pulmonary delivery [30].

Aptamers designed for tumor targeting, uptake, and endosomal escape have demonstrated efficacy in cell synthesis phase arrest and are particularly effective when used as a primer for subsequent therapies, such as cytarabine in lymphoma [31,32]. Aptamers have also been applied to nanoparticles and artificial natural killer cells as surface molecules conferring tumor trafficking function, checkpoint blockade with PD-L1-specific aptamers, 
and assistance with selective tumor cell perforation and lysis [33-35]. DARPins have been similarly conjugated to other agents such as oncolytic viruses, nanoparticles, and CAR-T cells to enhance their function in antibody-dependent cellular cytotoxicity and endocytosismediated toxin release [31]. The success of these immunotherapeutics in other disease models is encouraging for their application to GBM, though careful design for the specific immune challenges in GBM is crucial for their success.

Several clinical trials are underway investigating alternative scaffold-based ligandreceptors for various applications. Abicipar ${ }^{\circledR}$ (Allergan; Dublin, Ireland), a monospecific DARPin drug candidate targeting vascular endothelial growth factor (VEGF) in the treatment of macular degeneration, is currently in phase III clinical trials (NCT02462928 and NCT02462486). Trials with MP0250 have recently been initiated to investigate the effects of this bispecific DARPin to VEGF and hepacyte growth factor (HGF) in combination with the proteasome inhibitor bortezomib (NCT03136653) as well as in combination with the tyrosine kinase inhibitor osimertinib (NCT03418532) in multiple myeloma and non-small-cell lung cancer, respectively. In one Phase I trial, MP0250 was evaluated in the treatment of advanced solid tumors and found to have a "manageable" safety profile and demonstrated active binding to both targets after administration. More specifically, this trial reported dose-related adverse events of hypertension and proteinuria, which limited dose escalation in $30 \%$ of patients [36]. An affibody molecule with two identical IL17-binding modules joined by an albumin-binding domain is also being investigated in clinical trials (ABY-035; NCT02690142) [30]. Much can be learned from these existing clinical trials, from general safety and common adverse events to specific immune action for those drugs specifically designed to be immunotherapeutics. While no trials exist for such scaffolds in the treatment of GBM as of yet, they may provide unique advantages based on already discovered properties that warrant their application to GBM.

\subsubsection{Half-Life Extension Strategies}

Protein engineering or fusion can significantly improve the half-life of smaller drugs when time of circulation is important for therapeutic effect. Small protein drugs $(<50-60 \mathrm{kDa})$ have short half-lives of about one hour, as they are cleared rapidly and non-specifically by size exclusion in the kidney. Modifications to improve half-life must be mindful not to disturb the functionality of the drug or hinder extravasation. Albumin and IgG-Fc molecules are remarkably long-lived proteins that are commonly non-covalently linked to drugs to improve their retention through the kidney, as well as avoid endosomal degradation mediated by binding the largely ubiquitous neonatal Fc receptor [30].

Non-covalent association to albumin via a small (46 residue) albumin-binding domain from streptococcal Protein $\mathrm{G}$ is a common approach to extend the half-lives of scaffold-based proteins and simultaneously utilize FcRn-mediated recycling including affinity maturation to sub-picomolar binding affinity and subsequent deimmunization $[15,37]$. It was recently also shown to provide enhanced pharmacokinetic effects in humans when used in fusion with Affibody molecules (NCT02690142). ABD has also been used to prolong the halflives of Anticalins and antibody fragments, among other molecules in animal models [30]. MP0250, mentioned above in clinical trials for solid tumors, employs two ABDs that allow for binding of albumin once in patient serum and are designed to prolong the half-life of this drug [36].

\subsubsection{Stability Enhancement Strategies}

Protein therapeutic activity is tied to three-dimensional structure, which often relies on disulfide bonds. Thus, protein folding and efficacy are often threatened by non-reducing environments [38]. Engineered molecules can be devised to avoid this limitation through conformations that do not require disulfide bonds. For example, Monobodies and Fynomers are scaffolds that inherently do not require disulfide bonds for their stability [39] and Affibodies are known to be incredibly stable across a wide range of environments. Protein- 
polymer conjugates have been designed to alter the temperature and $\mathrm{pH}$ dependence of activity, solubility, and stability [38].

\subsubsection{Multivalency \& Multispecificity}

Multi-targeted strategies are essential in heterogeneous tumors, such as GBM, which can evade monotherapies more easily with antigen escape. The cancer immunopeptidome, or the repertoire of tumor-associated peptides displayed by major histocompatibility complex (MHC) class I molecules, is diverse and dynamic, changing as new mutations are accumulated through rapid and dysregulated tumor proliferation yielding neoantigens, or as treatments like radiation and chemotherapy influence gene expression and translation [23]. A multitude of immune cell types are implicated in tumor immunoevasion or anti-tumor activity, including CD8 + T cells, CD4 + helper T cells, dendritic cells, macrophages, and B cells, necessitating thoughtful, multipronged immunotherapeutic strategies [23]. Additionally, the cancer-immunity cycle progresses through many stages marked by various patterns of expression, including the preparatory phase (tumor antigen release and presentation, T-cell priming and activation) and effector stage (cytotoxic $\mathrm{T}$ lymphocyte trafficking, infiltration, recognition, and killing), that take place in multiple locations, including the tumor microenvironment and draining lymph nodes [39].

Engineering therapeutics with multispecificity to target different pathways is one promising strategy consisting of two major categories, non-obligate and obligate multispecific $[39,40]$. Non-obligate multispecific therapeutics are recombinant antibody-based molecules that simultaneously modulate two or more signaling pathways when binding their targets and are similarly efficacious to a mixture of distinct antibodies. Obligate multispecific therapeutics necessitate multiple binding specificities within one molecule to achieve efficacy. One category of obligate multispecific therapeutics is immune-cell engagers (BiTEs), which physically bring immune cells and tumor cells into proximity for killing by binding surface molecules on each. Choi et al., demonstrated CAR T cells secreting BiTEs against epidermal growth factor receptor (EGFR) that additionally interact with circulating $\mathrm{T}$ cells and allow their enhanced trafficking to the tumor site [41]. Other examples include antibody-drug conjugates, tertherbodies, and biologic matchmaker drugs that exert their function through binding multiple targets simultaneously [39].

Alternative scaffolds also serve as robust building blocks for multispecific therapeutics [39]. Fynomers, small ( $7 \mathrm{kDa})$ globular proteins derived from human Fyn kinase without disulfide bonds, are excellent candidates for this application. Examples include FynomAb, a HER2-specific Fynomer fused to the $\mathrm{N}$ or $\mathrm{C}$ terminus of heavy or light chain pertuzumab, and COVA322, an IL-17A-specific Fynomer fused to adalimumab [39]. Recently, a trispecific affibody fusion protein consisting of anti-amyloid beta, a scFv against $\mathrm{TfR}$ and an albumin binding domain, was shown to increase uptake into the cerebrospinal fluid $24 \mathrm{~h}$ after injection [39].

In the setting of this impressive repertoire of formats to choose from in designing therapeutics, new technologies that rapidly mine modelled combinations and screen candidates are essential to the advancement of this burgeoning field [29]. The rational design of protein-polymer conjugates has also been enhanced by the development of predictive tools and the breadth of synthetic tools that can attach polymers to proteins is rapidly expanding $[21,38,42,43]$.

\subsection{Biomaterials}

Biomaterials are commonly employed in studying and treating gliomas, with in vitro applications for modelling the tumor microenvironment and in vivo applications for sustained release of therapeutics in the resection cavity or draining lymph nodes. Materials engineering unlocks new possibilities for innovation in implantable, immunomodulatory materials that mimic and possibly surpass the intended actions of immunotherapies such as CAR T cells and vaccines [44]. 


\subsubsection{Polymeric Structures and Hydrogels}

Polymeric structures importantly allow for local and/or sustained release of active therapeutics and have been long a subject of investigation in gliomas, particularly as implants in the post-resection cavity [45-54]. BCNU wafers were approved for local delivery of carmustine to the glioma resection cavity in 1996, leading the pack on implantable local therapeutics for brain tumors [55,56]. Most recently, a clinical trial combining carmustine wafers, retifanlimab, temozolomide, and radiation therapy for the treatment of GBM has been initiated (NCT05083754).

Polymeric structures loaded with immunostimulatory agents, such as cytokines, immune checkpoint inhibitors, nanoparticles, immune-adjuvants, or immune cells, can be implanted in the post-resection cavity to provide controlled and sustained immune activation $[46,54,57]$. Ideal candidates for structures are non-immunogenic, biodegradable, and biocompatible. Poly lactic-co-glycolic acid (PLGA) is one of the most used FDA-approved biopolymers. One study investigating PLGA pre-loaded with GM-CSF, CpG-ODN, and tumor lysate demonstrated that it caused recruitment of dendritic cells to tumor tissue in glioma-bearing mice [49].

Biomaterials may also be devised to mimic the mechanism of action of existing immunotherapies but offer solutions to current limitations. For example, CAR T therapy success has been hindered by the limited infiltration of $\mathrm{T}$ cells into the tumor microenvironment and the immunosuppressive nature of GBM. In one design against 4T1 murine tumors, a nanovesicle containing nanogel loaded with active agents such as cisplatin, was found to be successful in tumor trafficking and retention, along with full regression of primary tumors and inhibition of metastatic tumors in $97 \%$ of subjects by immune activation [58].

Vaccines are another immune-activating approach widely investigated for anti-GBM therapy, although none have emerged as clear new standards of care, often lending to non-specific immunogenicity of vaccine boluses, multiplied by the typical multiple-dose treatment schedule. An innovative hydrogel approach has been utilized to solve this very limitation, employing electrostatic interactions to hold particles (ovalbumin in this case) within an implanted polymeric structure [59]. After initial implantation, looser-held particles would be released and taken-up by local antigen-presenting cells to stimulate a specific immune response, while slow release over time would act as "booster" doses to evoke secondary immunity without additional large boluses. This "single-dose vaccine" resulted in high IgG titer after 2 weeks without toxicity to vital organs [59].

Injectable hydrogels present another interesting delivery strategy for sustained release of immunotherapeutics, and importantly do not require tumor resection prior to implantation. Hydrogels mimic the extracellular matrix with crosslinked hydrophilic polymeric networks which can support the delivery of a variety of therapeutics $[49,56]$. Hydrogels must also meet tight thermal phase regulation specifications that allow the substance to be in gel form at body temperature but liquid at room temperature. Once implanted, scaffolds can be designed to release their payload constantly over time or in response to stimuli, such as light, electric or magnetic fields, $\mathrm{pH}$, temperature, or pressure $[49,60]$.

\subsubsection{Biosensing Material Implants}

Smart materials that are responsive to their environment would be highly desirable in treating the dynamic, immunosuppressive tumor microenvironment in GBM. While such materials are in early development, the possibilities opened by this technology are endless.

DNA structures are an exciting frontier in bioengineering with a high versatility of structures, including DNA cages, particles, polypods, and hydrogels, improving programmability and biocompatibility [49]. These structures can be applied to deliver immunostimulatory nucleic acids, such as CpG or ODN (unmethylated CpG motif) [49]. In one application, $\mathrm{CpG}-\mathrm{ODN}$ s loaded onto DNA tetrahedrons or tubes were shown to easily enter dendritic cells [49]. DNA-based structures have been particularly useful for biosensing material implants, due to this capacity for forming complex structure with biocompatibility and biodegradability. In one example, a woven matrix of DNA was designed 
to release anti-cancer compounds by self-degrading compound-holding "cocoons" in the acidic tumor microenvironment [61].

\subsubsection{Cell-Trapping Scaffolds}

For some applications, such as the loading of cell-based therapy or cancer cell-trapping, delivery platforms that more closely mimic the extracellular matrix are essential for improved cell retention. Electro-spun scaffolds have been shown to better approximate the natural extracellular matrix and can be composed of synthetic or natural materials, such as chitosan or cellulose [50,62,63]. In one study, an electro-spun scaffold of $261 \pm 45 \mathrm{~nm}$ diameter chitosan loaded with PLGA encapsulated SDF- $1 \alpha$ was implanted into the postresection cavity and demonstrated efficacy as a trap for migrating GBM cells expressing CXCR4 [62].

In another example, although not specific to GBM, a mixed-media scaffold was designed to trap migrating cancer cells with oligonucleotide aptamers andaccumulate doxorubicin with functionalized double-stranded DNA, demonstrating remarkable ability to capture and kill cancer cells with $90 \%$ efficacy within only $1 \mathrm{~h}$ [37]. This kind of strategy could be rationally extended to deliver cell therapies like CAR T cells for local immunotherapy with sustained release.

\subsection{Implantable Nanoreactors}

As covered thus far, implanted biomaterials are usually loaded with active agents prior to implantation and are designed to release their payload over relatively long periods of time, compared to the direct infusion of active agents. "Implantable nanoreactors," or implanted materials that carry out key reactions continuously over their lifetime, such as synthesizing or destroying target circulating molecules, could offer loading capacity-independent efficacy as intended reactions are continuous and catalysts are reused over time.

\section{Cell-Free Stabilized Enzyme Structures for Dynamic Therapy}

Wu et al., inspired by natural cell killing mechanisms employed by immune cells, investigated a nanogel loaded with a cascade of specific stabilized enzymes, yielding a dynamic, continuous "reactor" that could continuously convert high intratumoral superoxides to hydrogen peroxide and then to $\mathrm{O}_{2}$, disrupting the hypoxic tumor microenvironment and causing tumor regression $[60,64]$. A shell nanogel was also incorporated in this design to serve a dual purpose of stabilizing and protecting the active enzymes, as well as attract neutrophils with an embedded acid phosphatase [64].

Gilbert et al., demonstrated a "living biomaterial" created through co-culture of bacteria and yeast composed of bacterial cellulose and embedded yeast-secreted enzymes with preserved biocatalytic function [65]. This technology has not yet been evaluated from a therapeutic lens but would be highly valuable to the immunotherapeutic repertoire in its self-assembling production, cellulosic structure, and unlimited functional potential through engineering expression of various embedded enzymes. Theoretically, such a material could be implanted in the resection cavity of GBM and provide continuous, cell-free biocatalytic functions such as breakdown of immunosuppressive circulating molecules or generation of immunostimulatory agents through designed biocatalytic cascades. Injectable immunotherapies have previously been designed with multiphase functionality to track to and enter tumor cells and dissociate active molecules responsive to intracellular environments [66], but an implantable material with constant biocatalytic potential eliminates the need for dosing and relevant systemic toxicity. Cell-free stabilized enzymes have long been used in other industries with activity lifetimes approaching one year in industrial reactor environments for biomanufacturing [67]. 


\subsection{Other Considerations}

Sustainability and cost of production are important factors in the development of any novel therapeutic. Therapies that are easy to manufacture at a low cost through direct synthesis and are increasingly independent of petroleum-derived feedstocks will be wellpositioned to succeed and reach more patients in our evolving world. Recently, significant effort has been invested in developing an economically competitive sustainable production system for poly-malic acid, commonly used as a backbone in immunotherapeutics, from renewable biomass feedstocks, such as those generated from corn, sugarcane, or soybean refineries [68]. Bio-based generation of such components of therapeutics could significantly impact our societal independence from petroleum and starts at the lab bench.

\section{Discussion}

Bioengineered therapeutics have demonstrated advanced functionalities to improve patient outcomes in clinical trials and laboratory disease models. While such engineered therapeutics specifically designed for immunotherapy are few, they represent a growing opportunity for rational design in treating currently uncurable diseases, such as GBM (Table 1).

Crucial to the viability of any immunotherapeutic is biocompatibility and lack of general immunogenicity once administered, such that an adverse immune storm is triggered. As we have discussed, advances in bioengineering have allowed for new drugs with a tolerable safety profile when administered, opening the door to use these novel structures and backbones in the design of anti-GBM therapeutics that accel where currently available treatments fall short. Biomaterials, such as hydrogel "vaccines" and CARTmimicking nanovesicles loaded with sustained-release drug, that mimic intended actions of existing immunotherapuetics that have been slow to show significant effect in GBM but introduce key innovations allowing for potential success are promising for future therapeutic development.

There remains significant room for creativity in building novel bioengineered therapeutics. For example, cell trapping hydrogels can be employed to lure and activate exhausted $\mathrm{T}$ cells, which in GBM are thought to contribute greatly to immunosuppression and poor outcomes. Additionally, implantable nanoreactors of stabilized enzymes are an exciting frontier that provide long-term high throughput therapy of any kind. Future nanoreactors could be designed to breakdown immunosuppressive factors in circulation or locally produce active tumor-killing compounds by conversion of circulating factors either produced in the tumor microenvironment inherently or injected as part of the system design.

The bioengineering revolution has opened new possibilities in medicine, agriculture, food, and materials manufacturing that are only limited by our imagination. For immunotherapy in GBM, bioengineering has allowed for leaps of progress towards building smarter, safer medicines that have the potential to improve quality of life and patient prognosis. As we continue innovating in this field, cross-discipline collaboration between immunology, oncology, neurosurgery, infectious disease, engineering, etc. will be just as important as collaboration cross-industry, as synthetic biology has become popularized for its application across sectors. We can also apply some of what we learn and publish from engineering immunotherapies against brain cancer to biomanufacturing of all goods for human prosperity through the unifying power of bioengineering.

Author Contributions: Conceptualization, L.A.M.; writing-original draft preparation, L.A.M. and J.Y.W.; writing-review and editing, L.A.M., J.Y.W., P.S., N.K. and M.L.; visualization, L.A.M.; supervision, M.L. All authors have read and agreed to the published version of the manuscript.

Funding: This research received no external funding.

Conflicts of Interest: The authors declare no conflict of interest. 


\section{References}

1. Bi, W.L.; Beroukhim, R. Beating the odds: Extreme long-term survival with glioblastoma. Neuro Oncol. 2014, 16, 1159-1160. [CrossRef] [PubMed]

2. Eagles, M.E.; Nassiri, F.; Badhiwala, J.H.; Suppiah, S.; Almenawer, S.A.; Zadeh, G.; Aldape, K.D. Dendritic cell vaccines for high-grade gliomas. Ther. Clin. Risk Manag. 2018, 14, 1299-1313. [CrossRef]

3. Pardridge, W. Blood-brain barrier drug targeting: The future of brain drug development. Mol. Interv. 2003, 3, 51-90. [CrossRef]

4. Tellingen, O.; Yetkin-Arik, B.; Gooijer, M.C.; Wesseling, P.; Wurdinger, T.; Vries, H.E. Overcoming the blood-brain tumor barrier for effective glioblastoma treatment. Drug Resist. Updates 2015, 19, 1-12. [CrossRef] [PubMed]

5. Tang, W.; Fan, W.; Lau, J.; Deng, L.; Shen, Z.; Chen, X. Emerging blood-brain-barrier-crossing nanotechnology for brain cancer theranostics. Chem. Soc. Rev. 2019, 48, 2967-3014. [CrossRef]

6. Jackson, C.M.; Choi, J.; Lim, M. Mechanisms of immunotherapy resistance: Lessons from glioblastoma. Nat. Immunol. 2019, 20, 1100-1109. [CrossRef] [PubMed]

7. Nehra, M.; Uthappa, U.T.; Kumar, V.; Dixit, C.; Dilbaghi, N.; Mishra, Y.K.; Kumar, S.; Kaushik, A. Nanobiotechnology-assisted therapies to manage brain cancer in personalized manner. J. Control. Release 2021, 338, 224-243. [CrossRef]

8. Restrepo, P.; Yong, R.; Laface, I.; Tsankova, N.; Nael, K.; Akturk, G.; Sebra, R.; Gnjatic, S.; Hormigo, A.; Losic, B. Tumoral and immune heterogeneity in an anti-PD-1-responsive glioblastoma: A case study. Cold Spring Harb. Mol. Case Studies 2020, 6, 4762. [CrossRef]

9. Woroniecka, K.; Chongsathidkiet, P.; Rhodin, K.; Kemeny, H.; Dechant, C.; Farber, S.H.; Elsamadicy, A.A.; Cui, X.; Koyama, S.; Jackson, C.; et al. T-cell exhaustion signatures vary with tumor type and are severe in glioblastoma. Clin. Cancer Res. 2018, 24, 4175-4186. [CrossRef]

10. Schäfer, N.; Gielen, G.H.; Rauschenbach, L.; Kebir, S.; Till, A.; Reinartz, R.; Simon, M.; Niehusmann, P.; Kleinschnitz, C.; Herrlinger, U.; et al. Longitudinal heterogeneity in glioblastoma: Moving targets in recurrent versus primary tumors. J. Transl. Med. 2019, 17, 1846. [CrossRef] [PubMed]

11. Landry, A.P.; Balas, M.; Alli, S.; Spears, J.; Zador, Z. Distinct regional ontogeny and activation of tumor associated macrophages in human glioblastoma. Sci. Rep. 2020, 10, 76657. [CrossRef] [PubMed]

12. Wu, C.; Chen, C.H.; Lin, C.Y.; Feng, L.Y.; Lin, Y.C.; Wei, K.C.; Huang, C.Y.; Fang, J.Y.; Chen, P.Y. CCL5 of glioma-associated microglia/macrophages regulates glioma migration and invasion via calcium-dependent matrix metalloproteinase 2. Neuro Oncol. 2020, 22, 253-266. [CrossRef]

13. Weiss, S.A.; Wolchok, J.D.; Sznol, M. Immunotherapy of melanoma: Facts and hopes. Clin. Cancer Res. 2019, $25,5191-5201$. [CrossRef]

14. Paz-Ares, L.; Luft, A.; Vicente, D.; Tafreshi, A.; Gümüș, M.; Mazières, J.; Hermes, B.; Çay Şenler, F.; Csőszi, T.; Fülöp, A.; et al. Pembrolizumab plus Chemotherapy for Squamous Non-Small-Cell Lung Cancer. N. Engl. J. Med. 2018, 379, 2040-2051. [CrossRef]

15. Schuster, S.J.; Svoboda, J.; Chong, E.A.; Nasta, S.D.; Mato, A.R.; Anak, Ö.; Brogdon, J.L.; Pruteanu-Malinici, I.; Bhoj, V.; Landsburg, D.; et al. Chimeric antigen receptor T cells in refractory B-cell lymphomas. N. Engl. J. Med. 2017, 377, $2545-2554$. [CrossRef] [PubMed]

16. Neelapu, S.S.; Locke, F.L.; Bartlett, N.L.; Lekakis, L.J.; Miklos, D.B.; Jacobson, C.A.; Braunschweig, I.; Oluwole, O.O.; Siddiqi, T.; Lin, Y.; et al. Axicabtagene Ciloleucel CAR T-Cell Therapy in Refractory Large B-Cell Lymphoma. N. Engl. J. Med. 2017, 377, 2531-2544. [CrossRef] [PubMed]

17. Han, D.; Xu, Z.; Zhuang, Y.; Ye, Z.; Qian, Q. Current progress in CAR-T cell therapy for hematological malignancies. J. Cancer 2021, 12, 326-334. [CrossRef] [PubMed]

18. Reardon, D.A.; Brandes, A.A.; Omuro, A.; Mulholland, P.; Lim, M.; Wick, A.; Baehring, J.; Ahluwalia, M.S.; Roth, P.; Bähr, O.; et al. Effect of Nivolumab vs Bevacizumab in Patients with Recurrent Glioblastoma: The CheckMate 143 Phase 3 Randomized Clinical Trial. JAMA Oncol. 2020, 6, 1003-1010. [CrossRef] [PubMed]

19. Bagley, S.J.; Desai, A.S.; Linette, G.P.; June, C.H.; O'Rourke, D.M. CAR T-cell therapy for glioblastoma: Recent clinical advances and future challenges. Neuro Oncol. 2018, 20, 1429-1438. [CrossRef] [PubMed]

20. Sunshine, J.C.; Green, J.J. Nanoengineering approaches to the design of artificial antigen-presenting cells. Nanomedicine 2013, 8, 1173-1189. [CrossRef]

21. Rhodes, K.R.; Isser, A.; Hickey, J.W.; Ben-Akiva, E.; Meyer, R.A.; Kosmides, A.K.; Livingston, N.K.; Tzeng, S.Y.; Schneck, J.P.; Green, J.J. Biodegradable cationic polymer blends for fabrication of enhanced artificial antigen presenting cells to treat melanoma. ACS Appl. Mater. Interfaces 2021, 13, 7913-7923. [CrossRef] [PubMed]

22. Green, J.J. Immunoengineering has arrived. J. Biomed. Mater. Res. Part A 2021, 109, 397-403. [CrossRef] [PubMed]

23. Dersh, D.; Hollý, J.; Yewdell, J.W. A few good peptides: MHC class I-based cancer immunosurveillance and immunoevasion. Nat. Rev. Immunol. 2021, 21, 116-128. [CrossRef] [PubMed]

24. Trier, N.; Hansen, P.; Houen, G. Peptides, antibodies, peptide antibodies and more. Int. J. Mol. Sci. 2019, 20, 6289. [CrossRef] [PubMed]

25. Simeon, R.; Chen, Z. In vitro-engineered non-antibody protein therapeutics. Protein Cell 2018, 9, 3-14. [CrossRef] [PubMed]

26. Zaghmi, A.; Drouin-Ouellet, J.; Brambilla, D.; Gauthier, M.A. Treating brain diseases using systemic parenterally-administered protein therapeutics: Dysfunction of the brain barriers and potential strategies. Biomaterials 2021, 269, 120461. [CrossRef] [PubMed] 
27. Hlavničková, M.; Kuchař, M.; Osička, R.; Vaňková, L.; Petroková, H.; Malý, M.; Černý, J.; Arenberger, P.; Malý, P. ABD-derived protein blockers of human IL-17 receptor a as non-IgG alternatives for modulation of IL-17-dependent pro-inflammatory axis. Int. J. Mol. Sci. 2018, 19, 3089. [CrossRef] [PubMed]

28. Gularyan, S.K.; Gulin, A.A.; Anufrieva, K.S.; Shender, V.O.; Shakhparonov, M.I.; Bastola, S.; Antipova, N.V.; Kovalenko, T.F.; Rubtsov, Y.P.; Latyshev, Y.A.; et al. Investigation of inter and intratumoral heterogeneity of glioblastoma using TOF-SIMS. Mol. Cell. Proteom. 2020, 19, 960-970. [CrossRef] [PubMed]

29. Kintzing, J.R.; Interrante, M.V.F.; Cochran, J.R. Emerging Strategies for Developing Next-Generation Protein Therapeutics for Cancer Treatment. Trends Pharmacol. Sci. 2016, 37, 993-1008. [CrossRef] [PubMed]

30. Hober, S.; Lindbo, S.; Nilvebrant, J. Bispecific applications of non-immunoglobulin scaffold binders. Methods 2019, 154, 143-152. [CrossRef]

31. Shin, C.; Kim, S.S.; Jo, Y.H. Extending traditional antibody therapies: Novel discoveries in immunotherapy and clinical applications. Mol. Ther. Oncolytics 2021, 22, 166-179. [CrossRef]

32. Stuart, R.K.; Stockerl-Goldstein, K.; Cooper, M.; Devetten, M.; Herzig, R.; Medeiros, B.; Schiller, G.; Wei, A.; Acton, G.; Rizzieri, D. Randomized phase II trial of the nucleolin targeting aptamer AS1411 combined with high-dose cytarabine in relapsed/refractory acute myeloid leukemia (AML). J. Clin. Oncol. 2009, 27, 7019. [CrossRef]

33. Odeh, F.; Nsairat, H.; Alshaer, W.; Ismail, M.A.; Esawi, E.; Qaqish, B.; Bawab, A.A.; Ismail, S.I. Aptamers Chemistry: Chemical Modifications and Conjugation Strategies. Molecules 2020, 25, 3. [CrossRef] [PubMed]

34. Zhang, D.; Zheng, Y.; Lin, Z.; Liu, P.X.; Li, P.J.; Yang, H.; Tan, W. Equipping Natural Killer Cells with Specific Targeting and Checkpoint Blocking Aptamers for Enhanced Adoptive Immunotherapy in Solid Tumors. Angew. Chem.-Int. Ed. 2020, 59, 12022-12028. [CrossRef] [PubMed]

35. Yang, S.; Wen, J.; Li, H.; Xu, L.; Liu, Y.; Zhao, N.; Zeng, Z.; Qi, J.; Jiang, W.; Han, W.; et al. Aptamer-Engineered Natural Killer Cells for Cell-Specific Adaptive Immunotherapy. Small 2019, 15, 903. [CrossRef]

36. Baird, R.D.; Linossi, C.; Middleton, M.; Lord, S.; Harris, A.; Rodón, J.; Zitt, C.; Fiedler, U.; Dawson, K.M.; Leupin, N.; et al First-in-Human Phase I Study of MP0250, a First-in-Class DARPin Drug Candidate Targeting VEGF and HGF, in Patients With Advanced Solid Tumors. J. Clin. Oncol. 2020, 39, 145-154. [CrossRef]

37. Li, S.; Chen, N.; Gaddes, E.R.; Zhang, X.; Dong, C.; Wang, Y. A Drosera-bioinspired hydrogel for catching and killing cancer cells. Sci. Rep. 2015, 5, 14297. [CrossRef] [PubMed]

38. Baker, S.L.; Munasinghe, A.; Murata, H.; Lin, P.; Matyjaszewski, K.; Colina, C.M.; Russell, A.J. Intramolecular Interactions of Conjugated Polymers Mimic Molecular Chaperones to Stabilize Protein-Polymer Conjugates. Biomacromolecules 2018, 19, 3798-3813. [CrossRef]

39. Zhong, X.; D'Antona, A.M. Recent advances in the molecular design and applications of multispecific biotherapeutics. Antibodies 2021, 10, 13. [CrossRef]

40. Xuan, Y.; Guan, M.; Zhang, S. Tumor immunotherapy and multi-mode therapies mediated by medical imaging of nanoprobes. Theranostics 2021, 11, 7360-7378. [CrossRef] [PubMed]

41. Choi, B.D.; Yu, X.; Castano, A.P.; Bouffard, A.A.; Schmidts, A.; Larson, R.C.; Bailey, S.R.; Boroughs, A.C.; Frigault, M.J.; Leick, M.B.; et al. CAR-T cells secreting BiTEs circumvent antigen escape without detectable toxicity. Nat. Biotechnol. 2019, 37, 1049-1058. [CrossRef]

42. Baker, S.L. Structure-Function-Dynamics Relationships of Protein-Polymer Conjugates: Improving Activity and Stability in Non-Native Environments. Ph.D. Thesis, Carnegie Mellon University, Pittsburg, PA, USA, 2019.

43. Karlsson, J.; Tzeng, S.Y.; Hemmati, S.; Luly, K.M.; Choi, O.; Rui, Y.; Wilson, D.R.; Kozielski, K.L.; Quiñones-Hinojosa, A.; Green, J.J. Photocrosslinked Bioreducible Polymeric Nanoparticles for Enhanced Systemic siRNA Delivery as Cancer Therapy. Adv. Funct. Mater. 2021, 31, 2009768. [CrossRef] [PubMed]

44. Cornelison, R.C.; Munson, J.M. Perspective on translating biomaterials into glioma therapy: Lessons from In vitro models. Front. Mater. 2018, 5, 27. [CrossRef]

45. Tseng, Y.Y.; Chen, T.Y.; Liu, S.J. Role of polymeric local drug delivery in multimodal treatment of malignant glioma: A review. Int. J. Nanomed. 2021, 16, 4597-4614. [CrossRef] [PubMed]

46. Abdelkader, H.; Fathalla, Z.; Seyfoddin, A.; Farahani, M.; Thrimawithana, T.; Allahham, A.; Alani, A.W.; Al-Kinani, A.A.; Alany, R.G. Polymeric long-acting drug delivery systems (LADDS) for treatment of chronic diseases: Inserts, patches, wafers, and implants. Adv. Drug Deliv. Rev. 2021, 177, 113957. [CrossRef] [PubMed]

47. Thangam, R.; Patel, K.D.; Kang, H.; Paulmurugan, R. Advances in engineered polymer nanoparticle tracking platforms towards cancer immunotherapy—current status and future perspectives. Vaccines 2021, 9, 935. [CrossRef] [PubMed]

48. Kim, G.Y.; Tyler, B.M.; Tupper, M.M.; Karp, J.M.; Langer, R.S.; Brem, H.; Cima, M.J. Resorbable polymer microchips releasing BCNU inhibit tumor growth in the rat 9L flank model. J. Control. Release 2007, 123, 172-178. [CrossRef] [PubMed]

49. Abadi, B.; Yazdanpanah, N.; Nokhodchi, A.; Rezaei, N. Smart biomaterials to enhance the efficiency of immunotherapy in glioblastoma: State of the art and future perspectives. Adv. Drug Deliv. Rev. 2021, 179, 114035. [CrossRef]

50. Leach, D.G.; Young, S.; Hartgerink, J.D. Advances in immunotherapy delivery from implantable and injectable biomaterials. Acta Biomater. 2019, 88, 15-31. [CrossRef] [PubMed]

51. Jindal, A.; Sarkar, S.; Alam, A. Nanomaterials-Mediated Immunomodulation for Cancer Therapeutics. Front. Chem. 2021, 9, 46. [CrossRef] 
52. Galstyan, A.; Markman, J.L.; Shatalova, E.S.; Chiechi, A.; Korman, A.J.; Patil, R.; Klymyshyn, D.; Tourtellotte, W.G.; Israel, L.L.; Braubach, O.; et al. Blood-brain barrier permeable nano immunoconjugates induce local immune responses for glioma therapy. Nat. Commun. 2019, 10, 1-13. [CrossRef] [PubMed]

53. Correa, S.; Grosskopf, A.K.; Hernandez, H.L.; Chan, D.; Yu, A.C.; Stapleton, L.M.; Appel, E.A. Translational Applications of Hydrogels. Chem. Rev. 2021, 121, 11385-11457. [CrossRef] [PubMed]

54. Moore, K.M.; Murthy, A.B.; Graham-Gurysh, E.G.; Hingtgen, S.D.; Bachelder, E.M.; Ainslie, K.M. Polymeric Biomaterial Scaffolds for Tumoricidal Stem Cell Glioblastoma Therapy. ACS Biomater. Sci. Eng. 2020, 6, 3762-3777. [CrossRef]

55. Marcucci, F.; Corti, A.; Ferreri, A.J.M. Breaching the blood-brain tumor barrier for tumor therapy. Cancers 2021, $13,2391$. [CrossRef]

56. Stawicki, B.; Schacher, T.; Cho, H. Nanogels as a versatile drug delivery system for brain cancer. Gels 2021, 7, 63. [CrossRef]

57. Zhang, J.; Chen, D.; Liang, G.; Xu, W.; Tao, Z. Biosynthetic Polymalic Acid as a Delivery Nanoplatform for Translational Cancer Medicine. Trends Biochem. Sci. 2021, 46, 213-224. [CrossRef]

58. Zhai, Y.; Ran, W.; Su, J.; Lang, T.; Meng, J.; Wang, G.; Zhang, P.; Li, Y. Traceable bioinspired nanoparticle for the treatment of metastatic breast cancer via NIR-trigged intracellular delivery of methylene blue and cisplatin. Adv. Mater. 2018, $30,2378$. [CrossRef]

59. McHugh, K.J.; Guarecuco, R.; Langer, R.; Jaklenec, A. Single-injection vaccines: Progress, challenges, and opportunities. J. Control. Release 2015, 219, 596-609. [CrossRef]

60. Seidi, K.; Ayoubi-Joshaghani, M.H.; Azizi, M.; Javaheri, T.; Jaymand, M.; Alizadeh, E.; Webster, T.J.; Yazdi, A.A.; Niazi, M.; Hamblin, M.R.; et al. Bioinspired hydrogels build a bridge from bench to bedside. Nano Today 2021, 39, 1157. [CrossRef]

61. Sun, W.; Jiang, T.; Lu, Y.; Reiff, M.; Mo, R.; Gu, Z. Cocoon-like self-degradable DNA nanoclew for anticancer drug delivery. J. Am. Chem. Soc. 2014, 136, 14722-14725. [CrossRef]

62. Molina-Peña, R.; Mansor, M.H.; Najberg, M.; Thomassin, J.-M.; Gueza, B.; Alvarez-Lorenzo, C.; Garcion, E.; Jérôme, C.; Boury, F. Nanoparticle-containing electrospun nanofibrous scaffolds for sustained release of SDF-1 $\alpha$. Int. J. Pharm. 2021, 610, 121205. [CrossRef]

63. Bagó, J.R.; Pegna, G.J.; Okolie, O.; Mohiti-Asli, M.; Loboa, E.G.; Hingtgen, S.D. Electrospun nanofibrous scaffolds increase the efficacy of stem cell-mediated therapy of surgically resected glioblastoma. Biomaterials 2016, 90, 116-125. [CrossRef]

64. Wu, Q.; He, Z.; Wang, X.; Zhang, Q.; Wei, Q.; Ma, S.; Ma, C.; Li, J.; Wang, Q. Cascade enzymes within self-assembled hybrid nanogel mimicked neutrophil lysosomes for singlet oxygen elevated cancer therapy. Nat. Commun. 2019, 10. [CrossRef]

65. Gilbert, C.; Tang, T.C.; Ott, W.; Dorr, B.A.; Shaw, W.M.; Sun, G.L.; Lu, T.K.; Ellis, T. Living materials with programmable functionalities grown from engineered microbial co-cultures. Nat. Mater. 2021, 20, 691-700. [CrossRef] [PubMed]

66. Mu, M.; Chen, H.; Fan, R.; Wang, Y.; Tang, X.; Mei, L.; Zhao, N.; Zou, B.; Tong, A.; Xu, J.; et al. A Tumor-Specific Ferric-Coordinated Epigallocatechin-3-gallate cascade nanoreactor for glioblastoma therapy. J. Adv. Res. 2021. [CrossRef]

67. Rodriguez-Abetxuko, A.; Sánchez-DeAlcázar, D.; Muñumer, P.; Beloqui, A. Tunable Polymeric Scaffolds for Enzyme Immobilization. Front. Bioeng. Biotechnol. 2020, 8, 830. [CrossRef]

68. Zou, X.; Li, S.; Wang, P.; Li, B.; Feng, Y.; Yang, S.-T. Sustainable production and biomedical application of polymalic acid from renewable biomass and food processing wastes. Crit. Rev. Biotechnol. 2021, 41, 216-228. [CrossRef] 